\title{
Desarrollo e innovación tecnológica en ganadería ecológica y eficiente en la provincia del Sumapaz en los sectores productivos y educativos (Proyecto)
}

\section{Development and technological innovation and efficient organic farming in the province of Sumapaz in productive sectors and education (Draft)}

Moreno JA ${ }^{1}$, Acosta LM, Moreno V, Romero NJ, Guerrero JE, Alcázar HE, Arrieta $\mathrm{JM}$, Acero J y Camargo $\mathrm{MJ}^{2}$

${ }^{1}$ Profesor Universidad de Cundinamarca UDEC

${ }^{2}$ Profesores Universidad Nacional Abierta y a Distancia UNAD

zootjams@gmail.com, john.moreno@unad.edu.co

CONFERENCIA DEL I SEMINARIO INTERNACIONAL DE GANADERÍA AGROECOLÓGICA REALIZADO EN VILLAVICENCIO COLOMBIA, 11 y 12 de noviembre de 201

\section{RESUMEN}

Los sistemas tradicionales de producción en la región del Sumapaz, son esquemas que por impactos ambientales, sociales y económicos, necesitan la implementación de estrategias viables que los incorporen en la conceptualización de sistemas sostenibles-sustentables. El fortalecimiento de los conocimientos de cómo producir en un sistema bovino de manera eficiente y amigable con el ambiente, es una necesidad en la comunidad tanto para mantener sus condiciones de vida como para apoyar procesos de seguridad alimentaria. Con los objetivos de diseñar los Planes de Ordenamiento Predial (POP) basados en los recursos suelo, agua y bosque, implementar Sistemas Silvo-Pastoriles (SSP) demostrativos en el contexto de ganadería ecológica, capacitar en buenas prácticas ganaderas (BPG) para mejorar la calidad e inocuidad de la leche y la carne, procesos e indicadores reproductivos, lograr empresas ganaderas sostenibles y competitivas articuladas con el sector académico. $Y$ estandarizar un producto cárnico crudo procesado de origen bovino; se generó la alianza estratégica entre la UDEC, UNAD, Servicio Nacional de Aprendizaje (SENA), Comité de Ganaderos del Sumapaz (COMIGAN), Comité de cafeteros de Cundinamarca, Instituto Educativo Francisco José de Caldas-Pandi, Institución Educación Departamental Rural (I.E.D.R.): Zaragoza (Arbeláez), Aguabonita (Silvania), Subia (Subia) y la Institución Educativa Departamental Técnico Agropecuario (I.E.D.T.A).Calandaima (Cumáca-Tibacuy). En la región del Sumapaz-Cundinamarca, se seleccionaron 24 sistemas 
productivos, en los cuales se implementaron los POP mediante el contraste de información de entrevistas semi-estructuradas y observación directa, con topografía, hidrografía, zonas de riesgos y amenazas, zonas de protección y usos de suelo; obtenida en Planeación Municipal. Se establecieron 20 SSP en igual número de fincas experimentales. Se logró la capacitación en BPG y generación de proyectos productivos a 3717 estudiantes de secundaria, 12 docentes del área agrícola y biológica y 4737 productores bovinos. Mediante el uso de técnicas ultrasonográficas, se realizó valoración reproductiva de las hembras en los sistemas productivos y en los reproductores se realizó un diagnóstico por pruebas andrológicas (espermogramas y valoraciones corporales). En la socialización se generaron 3 días de campo, 32 capacitaciones, 2 giras a fincas certificadas; 28 publicaciones (guías, cartillas, libro, artículos, aplicación-web), 1 organización y 8 participaciones en eventos científicos, 36 trabajos de grado y una tesis de Maestría, 8 emisiones radiales y 3 televisivas. Se estandarizó un producto cárnico crudo procesado de origen bovino, típico de la región "ecovarita", con BPM. El proyecto demostró la posibilidad, importancia y aceptación de estrategias innovadoras basadas en SSP como alternativa mejoradora de los sistemas productivos bovinos y de la cual se puede articular diferentes sectores para aprender, investigar y generar impactos sociales, ambientales y productivos, fortalecedores de alianzas estratégicas que permiten la verdadera capacitación y apropiación de resultados desde la escolaridad e incrementar el grado de adopción tecnológica por parte de los productores. En el mediano plazo se debe continuar con el proceso de certificación de fincas ganaderas con BPG y a largo plazo, como fincas ecológicas, transformadas de los sistemas productivos convencionales a sistemas ecológicos, que generen un valor agregado en las salidas del sistema, en beneficio de los productores, la seguridad alimentaria y el impacto ambiental.

Palabras claves: Alianza estratégica, Buenas Prácticas Ganaderas, Sistemas Silvopastoriles, recursos biofísicos. 